\title{
Microwave Hyperthermia in Conjunction with Radiotherapy in Superficial Tumours: Correlation of Thermal Parameters with Tumour Regression
}

\author{
V Kouloulias ${ }^{1,2}$, S Triantopoulou ${ }^{1}$, E Efstathopoulos ${ }^{1}$, K Platoni ${ }^{1}$, J Kouvaris ${ }^{3}$, N Uzunoglou ${ }^{2}$,
} C Antypas ${ }^{3}$, P Karaiskos ${ }^{4}$, P Aggelakis ${ }^{4}$, J Vrouvas $^{4}$, N Kelekis ${ }^{1}$

\begin{abstract}
Objective: The aim of the present study is to evaluate the correlation between the thermal parameters of hyperthermia and the clinical outcome in patients with superficial tumours.

Methods: In this study, 20 patients were included with either submandibular lymph nodes from head and neck cancer, or breast cancer relapses post-mastectomy. They were treated with radiation in combination with one session of $433 \mathrm{MHz}$ microwave hyperthermia (1 hour, $42.5^{\circ} \mathrm{C}-46^{\circ} \mathrm{C}$ ). The dose of irradiation ranged from 54 to $60 \mathrm{~Gy}$. The thermal parameters calculated were the minimum volume temperature, the maximum volume temperature and the time interval where the volume temperature was greater than $44^{\circ} \mathrm{C}$.

Results: All patients responded positively to the combined treatment and $60 \%$ of the patients showed a complete response. Of the three parameters tested, the only parameter that was found to correlate with the reduction of the tumour diameter was the time with volume temperatures greater than $44{ }^{\circ} \mathrm{C}(p<$ 0.001, Spearman rho). No moderate toxicity was observed.

Conclusion: Microwave heating should be over $44{ }^{\circ} \mathrm{C}$ for favourable treatment response, when combined with radiotherapy. More patients are needed to confirm the above results.
\end{abstract}

Keywords: Breast cancer, head and neck cancer, radiotherapy, superficial hyperthermia, thermal parameters, response

\section{Hipertermia de Microonda de Conjunto con Radioterapia en los Tumores Superficiales: Correlación de los Parámetros Térmicos con la Regresión del Tumor}

\author{
V Kouloulias ${ }^{1,2}$, S Triantopoulou 1 , E Efstathopoulos ${ }^{1}$, K Platoni ${ }^{1}$, J Kouvaris ${ }^{3}$, N Uzunoglou ${ }^{2}$, \\ C Antypas ${ }^{3}$, P Karaiskos ${ }^{4}$, P Aggelakis ${ }^{4}$, J Vrouvas ${ }^{4}$, N Kelekis ${ }^{1}$
}

\begin{abstract}
RESUMEN
Objetivo: El objetivo del presente estudio es evaluar la correlación entre los parámetros térmicos de la hipertermia y el resultado clínico en pacientes con tumores superficiales.

Métodos: En este estudio, se incluyeron 20 pacientes con ganglios linfáticos submandibulares de cáncer de cabeza y cuello, o post-mastectomía por recidivas de cáncer de mama. Los pacientes fueron tratados con radiación en combinación con una sesión de hipertermia de microondas de $433 \mathrm{MHz}$ (1 hora, $42.5^{\circ} \mathrm{C}-46{ }^{\circ} \mathrm{C}$ ). La dosis de irradiación osciló entre 54 y $60 \mathrm{~Gy}$. Los parámetros térmicos calculados fueron la temperatura de volumen mínimo, la temperatura de volumen máximo y el intervalo de tiempo donde el volumen de la temperatura fue superior a $44^{\circ} \mathrm{C}$.

Resultados: Todos los pacientes respondieron positivamente al tratamiento combinado y el $60 \%$ de los pacientes demostrados una respuesta completa. De los tres parámetros probados, el único parámetro que se comprobó que se correlaciona con la reducción del diámetro del tumor fue el tiempo con
\end{abstract}

From: ${ }^{1}$ Radiotherapy Unit, $2^{\text {nd }}$ Department of Radiology, Medical School of Athens, Attikon University Hospital, ${ }^{2}$ Laboratory of Microwaves and Optical Fibers, National Technical University of Athens, Greece,

${ }^{3}$ Radiotherapy Unit, $1^{\text {st }}$ Department of Radiology, Medical School of
Athens, Aretaieion University Hospital, and ${ }^{4}$ Radiation Oncology Department, Hygeia General Hospital, Greece.

Correspondence: Dr V Kouloulias, Attikon Hospital, Rimini 1, Xaidari, 12462 Greece. Fax + 302 105326418, e-mail: vlkouloul@ece.ntua.gr 
temperaturas de volumen superiores a $44^{\circ} \mathrm{C}(p<0.001$, rho de Spearman). No se observó ninguna toxicidad moderada.

Conclusión: Calentamiento por microondas debe estar por encima de $44^{\circ} \mathrm{C}$ para que la respuesta sea favorable al tratamiento en combinación con radioterapia. Se requieren más pacientes para confirmar los resultados anteriores.

Palabras claves: Cáncer de mama, cáncer de cabeza y cuello, radioterapia, hipertermia superficial, parámetros térmicos, respuesta

West Indian Med J 2013; 62 (8): 753

\section{INTRODUCTION}

Hyperthermia seems to be an effective synergistic anticancer treatment, in conjunction or not with radiotherapy, chemotherapy and surgery. This method is based on the increase of tumour temperature up to $40^{\circ} \mathrm{C}-45^{\circ} \mathrm{C}$ by electromagnetic energy (1-3). Superficial hyperthermia is used for tumours that are at a depth less than $5 \mathrm{~cm}$ from the skin surface, such as breast cancer (BC), head and neck (HN) cancer or melanoma (4). Although there is great knowledge about BC, it still represents a major health problem, as there is an increasing number of cases that are reported yearly (5-7). On the other hand, despite the efficacy of the multimodal treatment - surgery, radiotherapy, chemotherapy and molecular targeted therapies - more than $50 \%$ of patients suffering from $\mathrm{HN}$ cancer will relapse or will have a metastatic disease (8). Hyperthermia definitely has a synergistic effect with irradiation for superficial tumours related to breast or head and neck cancers (9).

The aim of the study was to assess the correlation (primary endpoint) of thermal parameters of hyperthermia to both clinical outcome and tumour regression. The secondary endpoint was to evaluate the efficacy of hyperthermia to superficial tumours when added to radiotherapy.

\section{SUBJECTS AND METHODS}

In this study, 20 patients were included with superficial tumours whose depth was less than $5 \mathrm{~cm}$ from skin surface. These patients received radiotherapy in conjunction with hyperthermia (RTHT). The patients' characteristics are presented in Table 1. The patients that were enrolled in the study were suffering from submandibular lymph nodes related to $\mathrm{HN}$ cancer, or post-mastectomy relapses on the anterior front chest wall from BC. Before the beginning of the therapy, the

Table 1: Patients' characteristics: gender, age, tumour type and tumour diameter

\begin{tabular}{lc}
\hline Characteristics & $\mathbf{n}$ \\
\hline Male/female & $10 / 10$ \\
Median age - years (range) & $62(48-72)$ \\
Type of tumour & $7 / 20$ \\
Head and neck (cervical lymph nodes) & $8 / 20$ \\
Breast mastectomy & $5 / 20$ \\
Melanoma in-transit & $56.7(15.5)$ \\
Mean value of max tumour diameter $( \pm \mathrm{SD})$ & \\
\hline
\end{tabular}

patients received a computed tomography (CT) scan and the tumour diameter was measured. All patients received RTHT.

According to the study protocol, the patients that were enrolled met the following criteria:

* Histologically proven superficial cancer at depth less than $5 \mathrm{~cm}$ from skin surface.

* Contrast-enhanced CT scan performed before treatment.

* Normal electrocardiogram and normal chest wall Xray.

* Age 18-80 years old and life expectancy greater than two months.

* Karnofsky performance status $>70 \%$ and World Health Organization (WHO) status 0-1.

* Laboratory values (performed one week before study): absolute neutrophil count $>3000 / \mathrm{mm}^{3}$, platelet count $>100.000 / \mathrm{mm}^{3}$, haemoglobin $>10$ $\mathrm{g} / \mathrm{dL}$.

* Urea and serum creatinine lower than upper limit of laboratory normal.

* Total and direct bilirubin lower than upper limit of laboratory normal.

* Serum glutamic-oxaloacetic transaminase, serum glutamic-pyruvic transaminase lower than upper limit of laboratory normal.

* Alkaline phosphatase lower than upper limit of laboratory normal.

The exclusion criteria for the study were:

* Age $>80$ years old

* WHO status $>1$

* Patients with pacemaker and implanted electronic devices

* Patients with implanted stents

* Patients with fever before treatment

This study was conducted in accordance with the Declaration of Helsinki and all patients gave written informed consent which included the treatment and the related potential toxicity.

\section{Radiotherapy}

All patients received contrast-enhanced CT before treatment, for the location of the tumour and the determination of its diameter. This CT was used for the treatment planning of 
radiotherapy. Radiotherapy was realized either with $6 \mathrm{MV}$ $\mathrm{X}$-ray beam or $9 \mathrm{MeV}$ electron beam coming from a linear accelerator (6 MV Siemens or 15 MV Varian Clinac 2100C). The technique used was three-dimensional conformal radiotherapy. Patients received hypofractionated radiotherapy; dose per fraction varied from 275-300 cGy.

We used linear-quadratic (LQ) modelling in order to equate the hypofractionation schedule to the normalized total dose (NTD) if delivered in 2 Gy fractions (10). Thus, NTD represents the dose given in 2 Gy fractions that would give the equivalent biologic effect to the new hypofractionated dose:

$$
N T D-D_{n e w} \frac{d_{n x w}+\alpha / \beta}{2+\alpha / \beta}
$$

where $\mathrm{D}_{\text {new }}$ and $\mathrm{d}_{\text {new }}$ are, respectively the total dose and dose per fraction for a suggested hypofractionation scheme. Normalized total dose has been calculated and tabulated for late reacting tissues with $\alpha / \beta=3$ Gy (11). According to the previous calculations, the equivalent dose NTD varied from 54-60 Gy.

\section{Hyperthermia}

The hyperthermia session lasted one hour and was realized within one hour after radiotherapy. During hyperthermia, the intention was to reach the tumour temperature between $42{ }^{\circ} \mathrm{C}$ and $45^{\circ} \mathrm{C}$. The heating was superficial and was realized by waveguided applicators of circular or rectangular shape oper-

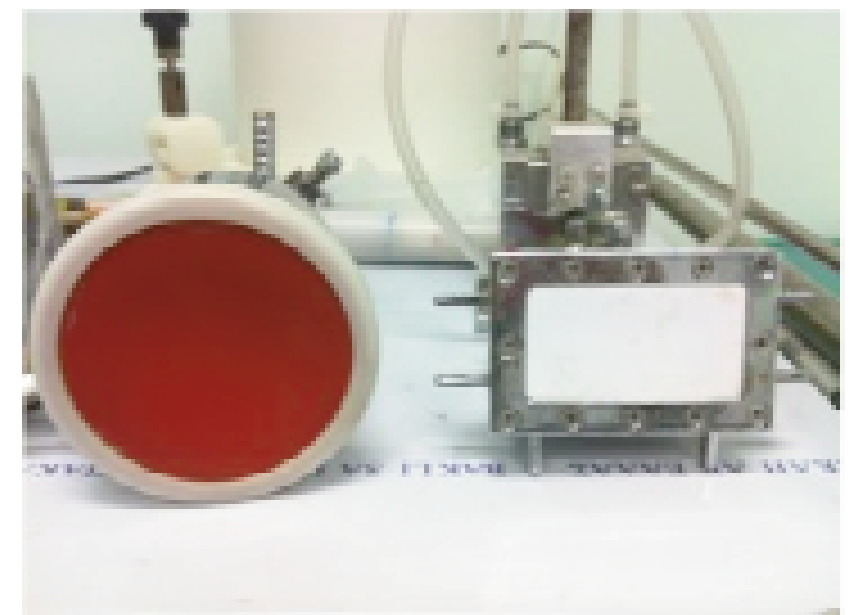

Fig. 1: Hyperthermia applicators of circular (diameter of $7 \mathrm{~cm}$ ) and rectangular shape $(5 \mathrm{~cm} \times 7 \mathrm{~cm})$

ating at the frequency of $433 \mathrm{MHz}$ (Figs. 1, 2). These applicators were constructed in the National Technical University of Athens. They were water cooled for the skin surface in order to avoid thermal blistering and burns which might occur on the skin from the electromagnetic power (12).

During the hyperthermia session, two thermocouples were used for recording the temperature. The first one was placed on the skin surface, near the applicator, during the whole session to ensure that the skin surface temperature did

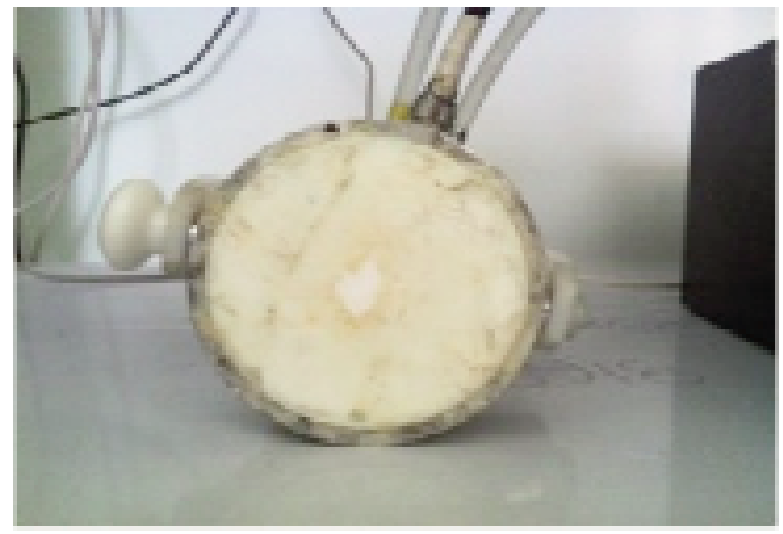

Fig. 2: Hyperthermia applicator of circular shape and diameter of 12 $\mathrm{cm}$

not exceed the therapeutic range. These data were not recorded; they were only monitored for safety reasons. The second thermocouple was inserted interstitially into the tumour after a local anaesthetic (Fig. 3). This thermocouple

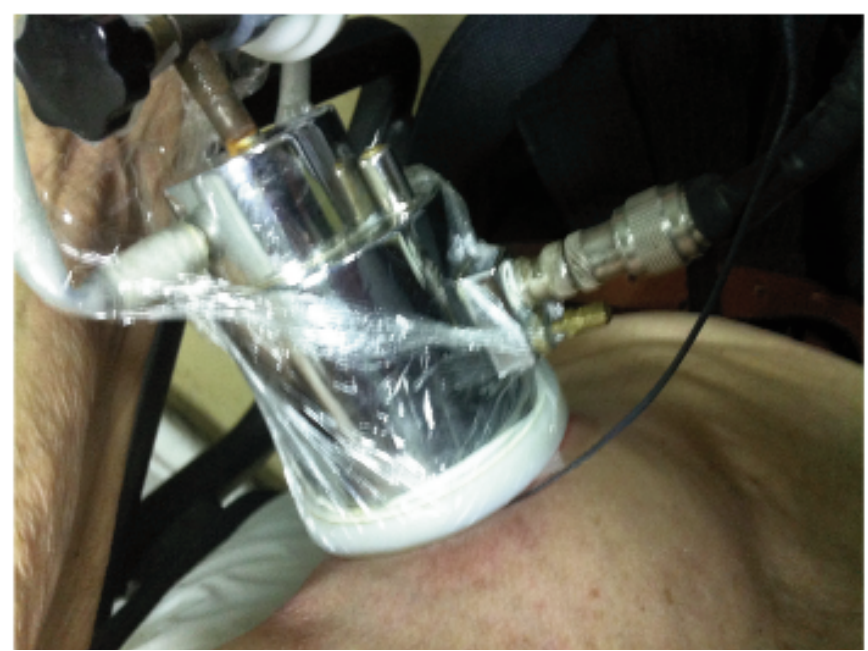

Fig. 3: Hyperthermia treatment with the $7 \mathrm{~cm}$ circular applicator on the front chest wall of a relapse breast cancer. The thermocouple is also shown at the footprint of the antenna.

had three points of measurement along its axis and counted the tumour temperature at depths $1,1.8$, and $2.6 \mathrm{~cm}$ during the whole hyperthermia session. These data were stored in a computer using a compatible data acquisition system (13).

The patients underwent one or more weekly hyperthermia sessions, depending on the irradiation schedule (one or four weeks).

\section{Treatment evaluation}

Two or three months after the completion of the therapy, each patient was subjected to another CT scan for the determination of the tumour reduction and the potential tumour response to the therapy.

It was considered:

* Complete response (CR): 100\% tumour regression 
* Partial response (PR): $\geq 50 \%$ tumour regression

* Stable disease (SD): $<25 \%$ tumour regression

* Progressive disease (PD): $\geq 25 \%$ increase in tumour volume

\section{Statistical analysis}

These tumour temperature data were entered onto a worksheet for further analysis. The thermal parameters that were calculated were:

* Tmin: the minimum tumour temperature during hyperthermia - average minimum for the three depths

* Tmax: the maximum tumour temperature during hyperthermia - average maximum for the three depths

* Time $\left(\mathrm{T}_{90}>44{ }^{\circ} \mathrm{C}\right)$ : time in minutes during which $90 \%$ of the recorded temperatures exceeded $44{ }^{\circ} \mathrm{C}-$ average for the three depths.

Finally, the correlation was assessed with Spearman rho correlation coefficient between the above-calculated thermal parameters and the decrease of the maximum tumour diameter. The significance level was set at 0.05 . The whole analysis was performed with SPSS version 10 (Chicago, IL, USA).

\section{RESULTS}

During the hyperthermia session, the tumour temperature data were recorded and were further analysed in order to calculate the minimum tumour temperature (Tmin), the maximum tumour temperature $(\mathrm{Tmax})$ and Time $\left[\mathrm{T}_{90}>44\right.$ $\left.{ }^{\circ} \mathrm{C}\right]$. As the thermocouple was recording the temperature for three different depths, the average for these parameters was calculated. The mean, standard deviation, median and range of Tmin, Tmax, Time $\left[\mathrm{T}_{90}>44{ }^{\circ} \mathrm{C}\right]$, irradiation dose and tumour diameter decrease are shown in Table 2. Among the

Table 2: Thermal parameters of hyperthermia

\begin{tabular}{ccccl}
\hline Parameter & Median & Mean & \pm SD & Range \\
\hline $\operatorname{Tmin}\left({ }^{\circ} \mathrm{C}\right)$ & 42.2 & 42.3 & 1.12 & $40-44.1$ \\
$\operatorname{Tmax}\left({ }^{\circ} \mathrm{C}\right)$ & 45 & 45 & 0.6 & $44-46$ \\
Time $\left[\mathrm{T} 90>44^{\circ} \mathrm{C}\right](\mathrm{min})$ & 30 & 29.4 & 12.5 & $6.8-54$ \\
Radiation dose $(\mathrm{Gy})$ & 58 & 57.8 & 2.3 & $54-60$ \\
Decrease of tumour max diameter $(\mathrm{mm})$ & 32 & 34.6 & 16.4 & $18-68$ \\
\hline
\end{tabular}

Tmin: minimum tumour temperature; Tmax: maximum tumour temperature; Time $\left[\mathrm{T} 90>44{ }^{\circ} \mathrm{C}\right]$ : time (in minutes) during which $90 \%$ of the recorded temperatures exceeded $44^{\circ} \mathrm{C}$.

patients, 15 patients $(75 \%)$ presented complete response while five patients $(25 \%)$ presented partial response. No stable or progressive disease was noted.

No correlation was found neither between the minimum nor the maximum tumour temperature and the therapeutic outcome (Spearman rho $=-0.0037, p=0.46$ and rho $=$ $-0.0052, p=0.27$, respectively). Moreover, no correlation was noted between decrease of tumour dimensions and irra- diation dose (Spearman rho $=0.04, p=0.18$ ). However, as shown in Fig. 4, a statistically significant correlation was noted between Time $\left[\mathrm{T}_{90}>44{ }^{\circ} \mathrm{C}\right]$ and the tumour reduction after the completion of the therapy (Spearman rho $=0.42$, $p<0.001)$.

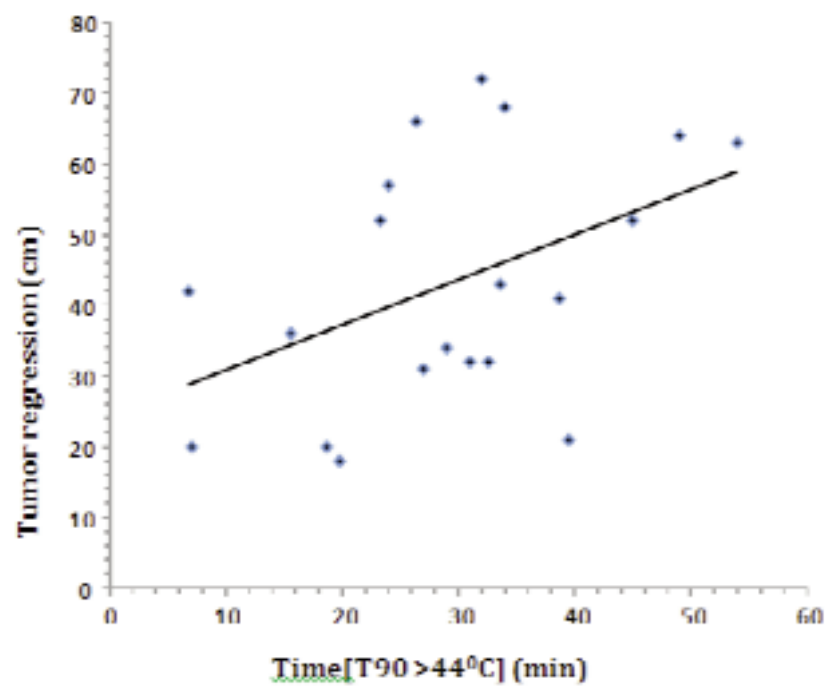

Fig. 4: Linear correlation between tumour regression and Time $[\mathrm{T} 90>44$ $\left.{ }^{\circ} \mathrm{C}\right]($ Spearman $\mathrm{rho}=0.42, p<0.001)$.

\section{DISCUSSION}

Many trials have already shown that RTHT for the treatment of superficial tumours is promising in its clinical outcome. In clinical oncology, superficial hyperthermia is mainly used for the treatment of breast cancer, head and neck cancer and melanoma. In most cases where patients received RTHT, it is shown that they responded positively to the treatment (1416). In addition, it has been observed that patients who are treated with RTHT have a greater complete response rate than those who are treated with irradiation alone. One of the greatest collections of data was realized by the collaboration of five different institutes - hospitals: it was found that the complete response rates were $59 \%$ and $41 \%$ with or without hyperthermia, respectively, while for patients that were previously irradiated the rates were $57 \%$ and $31 \%$, respectively $(1,17)$. Perez et al observed that hyperthermia helps the treatment of superficial tumours, especially of those with diameters $<3 \mathrm{~cm}$. They noticed that the complete response rates were increased from $40 \%$ to $62 \%$ for breast cancers, from $0 \%$ to $67 \%$ for trunk and extremities and from $38 \%$ to $50 \%$ for head and neck cancers (18). Gabriele et al (19) showed that for the patients with breast cancer -45 days after the completion of the therapy - the complete response rates were $65.9 \%$ and the partial response rates were $29.5 \%$. For patients with melanoma, the rates were $33.3 \%$ and $25 \%$, respectively; for patients with head and neck cancer, $40 \%$ and $13.3 \%$, respectively and for patients suffering from other kinds of superficial tumours the complete response rate was 
$60 \%$ and the non-response rate was $40 \%$. Overgaard et al (20) showed that $62 \%$ of melanoma lesions responded completely after the RTHT. As for breast cancer, the complete response rates that have been reported are $77.7 \%$, $71 \%$ and $74 \%(21-23)$. For head and neck cancer, the complete response rates that are reported are 55\% versus $31 \%$ for the patients that received only radiotherapy (24). In our study, the patients that were enrolled had superficial lesions and were treated with RTHT. It is important to mention that after the end of treatment, a reduction of the diameter was observed in all tumours and $75 \%$ of patients responded completely to RTHT, which is in accordance with the current literature.

The main aim of our study was to test the correlation between the thermal parameters of hyperthermia and the reduction of the tumour diameter after the completion of the therapy. Trials like those of Cox and Kapp $(25,26)$ have shown that between other thermal parameters (thermal dose $-\mathrm{T}_{90}$ ), the minimum tumour temperature correlates with the patients' response. Similar results were also reported from Kouloulias et al in a previous study of application of superficial hyperthermia in Greece (12). The minimum temperature has also been found to correlate with local control (1). However, in our trial, minimum temperature was not proven to be an important parameter for the clinical outcome. The same results were shown for the maximum tumour temperature. These contradictive results probably might be explained from the small number of patients.

The only thermal parameter that seems to correlate with the tumour regression is the Time $\left[\mathrm{T}_{90}>44{ }^{\circ} \mathrm{C}\right](p<$ 0.001). Similar results have been shown by Hand et al (27) as they proved that the time during which the temperature was greater than $42{ }^{\circ} \mathrm{C}$ correlates with complete response. In addition, Kouloulias et al (13), testing the application of hyperthermia in anterior chest wall recurrences from breast cancer, showed that there was a statistically significant correlation between Time $\left[\mathrm{T}_{90}>44{ }^{\circ} \mathrm{C}\right]$ and the disease-free interval to local relapse.

Hyperthermia has the advantage of being a painless therapeutic modality. The most common toxicity is thermal blistering, thermal burns and in some occasions, enhancement of acute reactions of radiation. It is more rarely reported that the interstitial placement of the thermocouple might cause pain and infections (28-31). All these reactions can be easily cured with medication. In our study, none of the patients reported pain or any reaction, except from a mild erythema.

The present study should be considered as a preliminary report. This work is ongoing since hyperthermia has been included in the routine clinical practice of our radiotherapy departments. In conclusion, it is considered necessary that more patients should be included in future clinical trials for further confirmation of the parameters that result in the optimization of the clinical application of the method. Efforts in hyperthermia must be made in order to retain the temperature inside the tumour above $44{ }^{\circ} \mathrm{C}$ for as long as possible.

\section{ACKNOWLEDGEMENTS}

The authors wish to thank the board of Aretaieion University Hospital for the approval of the method to be included in the radiotherapy clinical practice. This work was realized with the help of Dr Triantopoulou, Dr Uzunoglou, Dr Aggelakis, Dr Vrouvas and Dr Kouloulias who gave the hyperthermia treatment, while Dr Efstathopoulos and Dr Platoni were in charge of the treatment planning. Professors Kouvaris and Kelekis worked on the finalization of the current report. There was no conflict of interest.

\section{REFERENCES}

1. Zagar TM, Oleson JR, Vujaskovic Z, Dewhirst MW, Craciunescu OI, Blackwell KL et al. Hyperthermia combined with radiation therapy for superficial breast cancer and chest wall recurrence: a review of the randomised data. Int J Hyperthermia 2010; 26: 612-17.

2. Kouloulias VE. Hyperthermia in solid tumors. Aktinotechnologia 2003; 12: $38-45$.

3. Van der Zee J. Heating the patient: a promising approach? Ann Oncol 2002; 13: 1173-84.

4. Engin K, Leeper DB, Tupchong L, Waterman FM. Thermoradiotherapy in the management of superficial malignant tumors. Clin Cancer Res 1995; 1: 139-45.

5. Guarneri V, Conte PF. The curability of breast cancer and the treatment of advanced disease. Eur J Nucl Med Mol Imaging 2004; 31: 149-61.

6. Gonzalez-Angulo AM, Morales-Vasquez F, Hortobagyi GN. Overview of resistance to systemic therapy in patients with breast cancer. Adv Exp Med Biol 2007; 608: 1-22.

7. Cance WG, Carey LA, Calvo BF, Sartor C, Sawyer L, Moore DT et al. Long-term outcome of neoadjuvant therapy for locally advanced breast carcinoma: effective clinical downstaging allows breast preservation and predicts outstanding local control and survival. Ann Surg 2002; 236: 295-303.

8. Carla C, Daris F, Cecilia B, Francesca B, Francesca C, Paolo F. Angiogenesis in head and neck cancer: a review of the literature. $\mathrm{J}$ Oncol 2012; 2012: 1-9.

9. Triantopoulou S, Efstathopoulos E, Platoni K, Uzunoglou N, Kelekis N, Kouloulias V. Radiotherapy in conjunction with superficial and intracavitary hyperthermia for the treatment of solid tumors: survival and thermal parameters. Clin Transl Oncol 2013; 15: 95-105. Epub 2012 Nov 21.

10. Fowler JF: The linear-quadratic formula and progress in fractionated radiotherapy. Br J Radiol 1989; 62: 679-94.

11. Emami B, Lyman J, Brown A, Coia L, Goitein M, Munzenrider JE et al. Tolerance of normal tissue to therapeutic irradiation. Int J Radiat Oncol Biol Phys 1991; 21: 109-122.

12. Kouloulias V, Dardoufas C, Kouvaris J, Uzunoglu N, Plataniotis G, Vrouvas $\mathrm{J}$ et al. Combined radiotherapy and hyperthermia in the treatment of superficial carcinomas. The experience of the University of Athens Medical School. J BUON 2001; 6: 245-53.

13. Kouloulias VE, Dardoufas CE, Kouvaris JR, Gennatas CS, Polyzos AK, Gogas HJ et al. Liposomal doxorubicin in conjunction with reirradiation and local hyperthermia treatment in recurrent breast cancer: a phase I/II trial. Clin Cancer Res 2002; 8: 374-82.

14. Jones EL, Oleson JR, Prosnitz LR, Samulski TV, Vujaskovic Z, Yu D et al. Randomized trial of hyperthermia and radiation for superficial tumors. J Clin Oncol 2005; 23: 3079-85.

15. Welz S, Hehr T, Lamprecht U, Scheithauer H, Budach W, Bamberg M. Thermoradiotherapy of the chest wall in locally advanced or recurrent breast cancer with marginal resection. Int J Hyperthermia 2005; 21: 159-67. 
16. Zagar TM, Oleson JR, Vujaskovic Z, Dewhirst MW, Craciunescu OI, Blackwell KL et al. Hyperthermia for locally advanced breast cancer. Int J Hyperthermia 2010; 26: 618-24.

17. Vernon CC, Hand JW, Field SB, Machin D, Whaley JB, van der Zee J et al. Radiotherapy with or without hyperthermia in the treatment of superficial localized breast cancer: results from five randomized controlled trials. International Collaborative Hyperthermia Group. Int J Radiat Oncol Biol Phys 1996; 35: 731-44.

18. Perez CA, Pajak T, Emami B, Hornback NB, Tupchong L, Rubin P. Randomized phase III study comparing irradiation and hyperthermia with irradiation alone in superficial measurable tumors. Final report by the Radiation Therapy Oncology Group. Am J Clin Oncol 1991; 14: 133-41.

19. Gabriele P, Ferrara T, Baiotto B, Garibaldi E, Marini PG, Penduzzu G et al. Radio hyperthermia for re-treatment of superficial tumors. Int J Hyperthermia 2009; 25: 189-98.

20. Overgaard J, Bentzen SM, Overgaard J, Gonzalez Gonzalez D, Hulshof MCCM, Arcangeli G et al. Randomised trial of hyperthermia as adjuvant to radiotherapy for recurrent or metastatic malignant melanoma. Lancet 1995; 345: 540-3.

21. Gonzalez Gonzalez D, van Dijk JD, Blank LE. Chestwall recurrences of breast cancer: results of combined treatment with radiation and hyperthermia. Radiother Oncol 1988; 12: 95-103.

22. Lindholm CE, Kjellén E, Nilsson P, Weber L, Hill S. Prognostic factors for tumour response and skin damage to combined radiotherapy and hyperthermia in superficial recurrent breast carcinomas. Int $\mathrm{J}$ Hyperthermia 1995; 11: 337-55.

23. Van der Zee J, De Bruijne M, Mens JWM, Ameziane A, BroekmeyerReurink MP, Drizdal T et al. Reirradiation combined with hyperthermia in breast cancer recurrences: overview of experience in Erasmus MC. Int J Hyperthermia 2010; 26: 638-48.
24. Datta NR, Bose AK, Kapoor HK, Gupta S. Head and neck cancers: results of thermoradiotherapy versus radiotherapy. Int J Hyperthermia 1990; 6: 479-86.

25. Cox RS, Kapp DS. Correlation of thermal parameters with outcome in combined radiation therapy-hyperthermia trials. Int $\mathrm{J}$ Hyperthermia 1992; 8: 719-32.

26. Kapp DS, Cox RS. Thermal treatment parameters are most predictive of outcome in patients with single tumor nodules per treatment field in recurrent adenocarcinoma of the breast. Int J Radiat Oncol Biol Phys 1995; 33: 887-99.

27. Hand JW, Machin D, Vernon CC, Whaley JB. Analysis of thermal parameters obtained during phase III trials of hyperthermia as an adjunct to radiotherapy in the treatment of breast carcinoma. Int $\mathrm{J}$ Hyperthermia 1997; 13: 343-64.

28. Arcangeli G, Cividalli A, Nervi C, Creton G, Lovisolo G, Mauro F. Tumor control and therapeutic gain with different schedules of combined radiotherapy and local external hyperthermia in human cancer. Int J Radiat Oncol Biol Phys 1983; 9: 1125-34.

29. Arcangeli G, Nervi C, Cividalli A, Lovisolo GA. Problem of sequence and fractionation in the clinical application of combined heat and radiation. Cancer Res 1984; 44: 4857-63.

30. Leopold KA, Dewhirst MW, Samulski TV, Dodge RK, George SL, Blivin JL et al. Cumulative minutes with T90 greater than Tempindex is predictive of response of superficial malignancies to hyperthermia and radiation. Int J Radiat Oncol Biol Phys 1993; 25: 841-7.

31. Sherar M, Liu FF, Pintilie M, Levin W, Hunt J, Hill R et al. Relationship between thermal dose and outcome in thermoradiotherapy treatments for superficial recurrences of breast cancer: data from a phase III trial. Int J Radiat Oncol Biol Phys 1997; 39: 371-80. 